\title{
Itraconazole as a new pharmacotherapy method in haemangiomas
}

\author{
Przemysław Gałązka' ${ }^{1}$ Kamil Leis ${ }^{1}$, Ewelina Mazur ${ }^{1}$, Laura Nowowiejska²
}

${ }^{1}$ Department of Paediatric Haematology and Oncology, Faculty of Medicine, Collegium Medicum in Bydgoszcz, Nicolaus Copernicus University in Torun, Poland

2Department of Dermatology and Venereology, Faculty of Medicine, Collegium Medicum in Bydgoszcz, Nicolaus Copernicus University in Torun, Poland

Adv Dermatol Allergol 2021; XXXVIII (6): 1122-1123

DOI: https://doi.org/10.5114/ada.2021.112284

Early childhood haemangioma ranks as one of the most common childhood neoplasms. This type of birthmark occurs in about $5 \%$ of all infants, most often during the first through fifth months of age. These benign tumours can develop in both internal organs (e.g., the liver) and on the skin, which is a particularly frequent location [1]. Currently, the standard of treatment is pharmacotherapy with beta blockers. Propranolol is the most commonly prescribed beta blocker due to its high efficacy and safety profile confirmed by many studies. As an alternative, other beta blockers can be used, including atenolol, timolol, and imiquimod [1-3]. In case of no satisfactory effect after pharmacotherapy, laser therapy or surgical treatment may be recommended $[1,2]$.

Itraconazole, a systemic triazole drug with strong anti-angiogenic properties, has been proven in numerous studies to be an effective treatment for haemangiomas. Treatment of mycoses is the classic use for itraconazole $[4,5]$. Ran et al. describes the first documented therapeutic success for treating childhood skin haemangiomas with itraconazole. This study involved 6 children ( 5 girls, 1 boy, all between 2 and 5 months of age). Researchers administered itraconazole at a dose of 5 milligrams per kilogram $(\mathrm{mg} / \mathrm{kg})$ of body weight; the therapy lasted from 2 to 9 weeks. Regression of angioma occurred in every child, with an efficacy rate of at least $80 \%$. Despite the promising results, however, the authors noted that they did not fully understand the antifungal drug's mechanism of action on these haemangiomas [4]. This mechanism was investigated in 2019 by Chen et al. using in vitro tests on infantile primary haemangioma endothelial cell lines (HemEC) and endothelial cells of mouse hemangioendothelioma (EOMA) cell lines, wherein it was found that itraconazole caused an increase in apoptosis while inhibiting angiogenic and proliferative processes. Moreover, researchers observed a significant decrease in the concentration of PDGF-D (platelet-derived growth factor D), which resulted in inhibition of activity of PI3K, 4E-BP1, p7-S6K, Akt (by blocking the attachment of phosphate residues) and platelet-derived growth factor- $\beta$ (PDFG- $\beta$ ) [6].

Also in 2019, a comparative analysis was conducted by Bessar et al. to determine the efficacy of using itraconazole and propranolol to treat early childhood haemangiomas. Thirty-six patients ( 8 boys and 28 girls) were divided into two groups of 18 people. One group was assigned an antifungal drug used for a maximum period of 3 weeks at a dose of $5 \mathrm{mg} / \mathrm{kg}$ body weight once daily. In the other group, a $\beta$-blocker was introduced and used for 6 months at a dose ranging from 0.5 to $1.5 \mathrm{mg} / \mathrm{kg}$ body weight, administered three times a day [7].

The researchers proposed a therapy-effectiveness scale and suggested three outcomes: good response, partial response, and poor response. Only four of all patients in the propranolol group achieved good responses while eight good responses were achieved in the itraconazole group. Of the total participant group getting itraconazole, 8 achieved good responses, 8 achieved partial responses, and the remaining 2 responded poorly. Of those getting propranolol, 4 achieved good responses, 12 achieved partial responses, and the remaining 2 experienced poor results. Itraconazole was found to be more effective for treating infantile angiomas [7]. However, the small sample size should be considered.

A decrease in angiopoietin-2 levels was also observed in patients treated with both a $\beta$-blocker and an antifungal drug. For the propranolol group, the average angiopoietin-2 level dropped from 68 to 43; the itraconazole group measured a drop from 92 to 62 . It can be concluded that both

Address for correspondence: Przemysław Gałązka MD, PhD, Oddział Kliniczny Chirurgii Ogólnej i Onkologicznej Dzieci i Młodzieży, Szpital Uniwersytecki nr 1 im dr Jurasza, 9 Skłodowskiej-Curie St, 85-094 Bydgoszcz, Poland, phone: +48 525854015 , fax: +48 52 585 4095, e-mail: galazkaprzemek@hotmail.com

Received: 24.09.2020, accepted: 26.11.2020. 
drugs reduced the concentration of angiopoietins with similar effectiveness and had similar safety profiles [7].

Pharmacotherapy with the triazole drug is also effective for treating adults with haemangiomas. Wu et al. reported effective use of itraconazole treatment in a 35-year-old woman with a tufted angioma on her head. The angioma caused pain and hair loss. She was prescribed 400 milligrams (mg) a day, orally, for 3 months. This therapy resulted in the cessation of pain after a few days, followed by hair regrowth and a significant reduction in tumour size [8].

A separate study compared propranolol versus itraconazole for treating haemangioma in adults. Each of two groups consisted of 15 study participants. One group was prescribed $40 \mathrm{mg} /$ day of propranolol, the other $200 \mathrm{mg}$ daily of itraconazole. Sodium tetradecyl sulfate was also administered [9]. Haemangiomas were located on the tongue, palate, and various locations on the head and neck. In the case of $\beta$-blocker therapy, tumour size, measured in centimetres cubed, was reduced by approximately $95 \%, 99.9 \%$, and $88 \%$, respectively. For the itraconazole-treated group, these values were approximately $94 \%, 97.8 \%$, and $84.5 \%$, respectively. Additionally, the propranolol group saw a reduction in the haemangioma size by $91.9 \%$; tumour-size reduction in the itraconazole group was $89 \%$. Complete regression of the lesion was reported in 3 patients receiving $\beta$-blocker therapy but only one in the antifungal drug group. These efficacy outcomes can be considered similar, with a slight advantage in favour of propranolol therapy. Both drugs showed similar safety profiles, including all side effects that occurred during the pharmacotherapy phase of the study [9].

In the field of medical literature, multiple studies exist that confirm the efficacy of using itraconazole for treating haemangiomas for both paediatric and adult populations. Itraconazole presents as a suitable alternative to oral propranolol, which is the current treatment standard. For paediatric patients, itraconazole therapy seems to be more effective than $\beta$-blockers, based on analyses conducted thus far.

In addition to high degrees of efficacy and safety, the antifungal drug also seems to be interesting due to its shorter treatment time and faster effects. Yet another advantage is its lack of influence on blood pressure.

The small number of studies involving small numbers of patients should be noted when comparing these drugs for treatment options. For the routine introduction of triazole in the treatment of haemangiomas, further analyses are required to confirm efficacy and safety, especially in the paediatric population.

\section{Conflict of interest}

The authors declare no conflict of interest.

\section{References}

1. Krowchuk DP, Frieden IJ, Mancini AJ, et al. Clinical practice guideline for the management of infantile hemangiomas. Pediatrics 2019; 143: e20183475.

2. Droitcourt C, Kerbrat S, Rault C, et al. Safety of oral propranolol for infantile hemangioma. Pediatrics 2018; 141: e20173783.

3. Raphael MF, Breugem CC, Vlasveld FA, et al. Is cardiovascular evaluation necessary prior to and during beta blocker therapy for infantile hemangiomas? A cohort study. J Am Acad Dermatol 2015; 72: 465-72.

4. Ran Y, Chen S, Dai Y, et al. Successful treatment of oral itraconazole for infantile hemangiomas: a case series. I Dermatol 2015; 42: 202-6.

5. Pace JR, DeBerardinis AM, Sail V, et al. Repurposing the clinically efficacious antifungal agent itraconazole as an anticancer chemotherapeutic. J Med Chem 2016 28; 59: 3635-49.

6. Chen S, Zhuang K, Sun K, et al. Itraconazole induces regression of infantile hemangioma via downregulation of the platelet-derived growth factor-D/PI3K/Akt/mTOR pathway. J Invest Dermatol 2019; 139: 1574-82.

7. Bessar H, Kandil AH, Nasr NM, et al. Itraconazole versus propranolol: therapeutic and pharmacologic effect on serum angiopoietin- 2 in patients with infantile hemangioma. J Dermatolog Treat 2019; 31; 1-25.

8. Wu W, Shi J, Li Z, et al. Oral itraconazole for the treatment of giant tufted angioma with hair loss arising during pregnancy: a case report. J Dermatol 2020; 47: e35-6.

9. Panditray S, Acharya S, Prusty N, et al. Management of head and neck hemangiomas in adults: oral propranolol versus oral itraconazole in conjugation with injection sodium tetra decyl sulphate. Indian J Otolaryngol Head Neck Surg 2019; 71 (Suppl 1): 566-73. 